\title{
RESEARCH PAPER \\ THE EFFECT OF SMALLHOLDER LIVESTOCK PRODUCTION ON INCOME OF FARM HOUSEHOLDS IN NORTHERN GHANA
}

\author{
*S. T. Baidoo, H. Yusif and U. Anwar \\ Department of Economics, KNUST, Kumasi \\ *Corresponding author: samueltawiahbaidoo@yahoo.com \\ hadraty@yahoo.co.uk \\ umar.anwar@gmail.com
}

\begin{abstract}
This paper investigates the effect of smallholder livestock production on income among farm households in northern Ghana. Questionnaires were administered to 300 household heads and ordinary least squares estimation technique was applied to the dataset. The dependent variable was income and measured by total annual income received from farm and non-farm activities by household heads. The independent variable of interest was tropical livestock unit measured by flock size. We also included farm size, household size, gender, age, educational level, distance to market, dependency ratio and access to formal credit as control variables. We found that smallholder livestock production and farm size increase income whilst distance to market and dependency ratio reduce income. Based on evidence of the positive relationship between livestock production and household income in this paper, it is recommended that policies to promote smallholder livestock production should be embarked upon to increase income. This is likely to improve livelihood and reduce poverty among the poor rural folks in the northern regions of Ghana.
\end{abstract}

Keywords: Livestock production, farm households, income, poverty, Northern Ghana

\section{INTRODUCTION}

Poverty is one of the major challenges facing the developing world. According to Hoynes (2012) it is a family concept and all persons in the same family have the same poverty status. Lower household income is one of the factors worsening poverty situations for many developing countries and especially among the SubSaharan African countries. Poverty has been defined by the World Bank in absolute terms as persons who live on less than US\$1.25 and US $\$ 2.00$ per day for extreme and moderate poverty respectively.

Chen and Ravallion (2008) argued that there are roughly 2.6 billion persons in developing countries who live on less than US\$2 a day and 1.4 billion of them survive on less than 
US\$1.25 a day. World Bank (2007) reported that poverty was worse in Sub-Saharan Africa than the other developing regions and one in every two persons faced extreme poverty and lived on less than US\$1.25 a day. According to the Ghana Living Standard Survey (round 6), 2.2 million people representing $8.4 \%$ do not earn annual income of GH $\Varangle 792.05$ and are classified as being extremely poor. This category of people cannot feed themselves even if they were to spend all their income on food. Regarding the upper poverty line, there are 6.4 million Ghanaians (24.2\%) who do not earn annual income of $\mathrm{GH} \notin 1,314.00$ and are also considered poor. This high poverty rate has been attributed to the low level of incomes individuals earn from their respective economic activities (Ghana Statistical Service, 2014c).

Smaller household income has been reported to exert negative impact on families and especially on children's education. Previous studies (Brooks-Gunn and Duncan, 1997; Guo and Harris, 2000; Klebanov et al., 1994; Aber et al., 1997; Yoshikawa et al., 2012; Hoynes, 2012; Eamon, 2001; Yusif and Ali, 2013; Yusif, 2015) have reported that poverty resulting from low income prevents a child from attending pre -school, makes a child drop out of school, perform badly in school, involve in early marriage, involve in criminal activity, have poor mental and physical health, involve in delinquent behaviour, have short life expectancy and likely not to get a reliable and well paid job.

Since 1983 the government of Ghana has implemented policies and programmes to enable households and individuals to earn substantial income in order to alleviate poverty. These include the Programme of Action to Mitigate the Social Cost of Adjustment (1987), Ghana Poverty Reduction Strategy (2003-2005), Growth and Poverty Reduction Strategy (20062009), National Social Protection Strategy (2007) and Livelihood Empowerment Against Poverty Programme (2008). These programmes and policies have focused on educational reforms (basic education for all), irrigation sys- tem of farms of households, revamping the vocational and technical institutions for the youth between the ages of 15-18 years, direct support for human development and provision of basic services such as health care, portable drinking water among others.

As a result, there has been improvement in livelihood among households and a steady decline in poverty from the national average of $51 \%$ in 1991 to $24.25 \%$ in 2013 (Ghana Statistical Service, 2014c). Unfortunately, this reduction in poverty through enhancement in income among others has not been even throughout the country. Households in the Savanna Zone comprising the three northern regions (Upper East, Upper West and Northern Region) have been associated with low income and extreme poverty. Indeed, four in every ten persons are poor in the Upper East Region (44.4\%), seven out of ten in the Upper West Region (70.7\%) and one in every two $(50.4 \%)$ in the Northern Region (Ghana Statistical Service, 2014b). A child in these regions is likely to drop out of school, get involved in early child marriage and be malnourished than a child in any other part of Ghana.

The major economic activities and sources of income for majority of households in these regions are crop farming and animal rearing (Ghana Statistical Service, 2014b). Some studies (Anang et al., 2015; Udo et al., 2011) have reported that the contribution of these smallholder farmers to agricultural and economic development cannot be underestimated especially in livelihood and income enhancement. Income from household crop farming in the three northern regions of Ghana is seasonal due to much reliance on rainfall (Adams and Ohene -Yankyera, 2014). According to the Food and Agriculture Organization (2012) technologyoriented agricultural projects have not been successful at significantly increasing household income and reducing broad-based poverty in the developing economies and as a result, the Animal Production and Health Division of the Food and Agriculture Organization of the 
United Nations launched Pro-Poor Livestock Policy Initiative. Livestock production has become a key policy option for policy makers and stakeholders for increasing income and also an attempt to improve livelihood of rural households (Food and Agriculture Organization, 2012). Earlier, Asafu-Adjei and Dantankwa (2001) have reported that production of livestock is likely to increase household income and also ensure food security among rural households if optimally and sustainably exploited.

In Ghana, the three northern regions constitute the center of livestock production where over $63 \%$ of cattle, $59 \%$ of sheep, $42 \%$ of goats, $23 \%$ of chicken and about $80 \%$ of guinea fowls are being reared (Ghana Statistical Service, 2014a). They are mostly smallholder livestock producers and engage in subsistence and family farming with low income, low external input, low output or low-technology livestock keeping. The generic definition for smallholders have been used in referring to famers with fewer than 50 small ruminants (Sheep/Goats) or fewer than 25 cattle or fewer than 1,000 poultry (MOFA/DFID, 2002).

Little research has been conducted regarding the influence of livestock production on household income in the Ghanaian context. Naminse (2010) studied the effect of ruminant production on household income and food security in the Talensi-Nabdam District of the Upper East Region of Ghana using a sample of 60 households. The main limitation of Naminse (2010) for policy making was the use of only descriptive statistics for the analysis and also the relatively small sample size used. In this present paper we have used a sample of 300 household heads and also employed the ordinary least square (OLS) estimation technique to examine the relationship between livestock production and household income. Our results are expected to aid policy makers and government in the formulation of policies to increase household income which will subsequently reduce the extreme poverty that has engulfed people in the northern part of Ghana.

\section{REVIEW OF PREVIOUS STUDIES}

Scores of studies have investigated the influence of smallholder livestock production on household income in Sub-Sahara Africa (Kafle, 2014; Inoni, 2010; Yusuf et al., 2008; Ntanyoma 2010; Naminse, 2010; Alam, 1997). For example, Kafle (2014) studied the impact of the livestock donation programme (dairy cow, goat and draft cattle) on poverty and food security measures in Zambia. He applied pooled poisson and probit estimation techniques to data from 300 households in the Copper-belt province. Kafle (2014) found that all beneficiaries of animals experienced significant increase in livestock revenue and thus contributed to poverty alleviation. The consumption expenditure and frequency of diary/meat consumption at the end of the fourth round also increased. Talukder (2014) also examined the determinants of income of rural household in Bangladesh. Using secondary data from 1985, 1986 and 2005, ordinary least square estimation technique was applied to the dataset. The result showed that household size and land area for farming were positively and significantly associated with rural household income. An increase in household size increases household income as larger farm size could be cultivated. This could result in more output hence increase in income.

To assist policy makers in designing policies that could promote the welfare of smallholder farmers in Burundi, Nzabakenga et al. (2013) investigated the determinants of income of smallholder farmers. They applied descriptive statistics and ordinary least square estimation technique to dataset obtained from 218 smallholder farmers. The explanatory variables consisted of age, gender, education level, and marital status of smallholder farmers. Others are fertilization level and condition of irrigation. The result revealed that family size and farm size were positively correlated with income of smallholder farmers. A large family size has comparatively more labour which enhances more farm land cultivation, increase output and 


\section{Baidoo et al.}

income levels. The study however did not find any significant association between age, gender, marital status, fertilization level and condition of irrigation with income of smallholder farmers.

In Nigeria, Inoni (2010) examined the effect of smallholder livestock production on poverty reduction. He used 218 rural dwellers engaged in small scale farming in 20 communities in the Central Agricultural Zone of Delta State. His dependent variable was flock size among smallholder livestock producers and the independent variables included household size, annual income and gender of household head. The study indicated that livestock income exerted positive effect on the lives of farmers through improved nutrition and food security which tend to reduce poverty. Similarly, Yusuf et al. (2008) applied descriptive statistics and logistic estimation technique to 200 households selected from two local government areas in Ibadan Metropolis of Oyo State, Nigeria. They revealed that poverty was as high as $50 \%$ among households that engaged in crop farming. For households that engaged in mixed farming it was $37 \%$. However, for livestock farmers it was $17 \%$. This indicated that households who engaged in smallholder livestock production had lower poverty levels.

Ntanyoma (2010) studied the effect of increase in number of livestock on income in Rwanda. He applied descriptive and propensity score matching techniques to 333 households (210 received cows and 123 formed the control group). The study showed that households who received cows had increased their income and thus reduced poverty. In Ghana, Naminse (2010) studied the impact of ruminant production on household income and food security among the people of Talensi-Nabdam District in the Upper East Region. The sample size was 60 ruminants farmers and descriptive statistics was used to analyze the data. Naminse (2010) reported that sales of ruminants contributed roughly $36.10 \%$ to the annual income of smallholder livestock producers in the TalensiNabdam District.
In Asia, Alam (1997) investigated the impact of intervention by the smallholder livestock development project (SLDP) on the socio-economic conditions of poor people in rural areas. Descriptive statistics was applied to a sample of 1,000 disadvantaged women. The study revealed that the income of the women involved had increased and their socio-economic conditions improved. This impacted positively on their empowerment and participation in decision making. Also, Akter (2011) examined the effect of the poverty alleviation programme through the promotion of poultry production on the livelihood of smallholder livestock farmers in Bangladesh for the period 2006-2008. Akter (2011) applied self-assessed measurement and multinomial logistic estimation technique to individual data collected from 400 women smallholder farmers. The study revealed that poultry share of income was $4.3 \%$ in 2006 and increased to $7.1 \%$ in 2008. Again, livestock income share also increased from $15 \%$ in 2006 to $18 \%$ in 2008 . This indicates that the alleviation programme introduced really brought relief on the smallholder livestock farmers in Bangladesh.

\section{METHODOLOGY}

Data, variable description and model specification

This section presents data acquisition procedures, description of variables and the model specification for this paper.

\section{Data and variable description}

The data for our study was obtained through questionnaires administered to a sample of 300 respondents (smallholder livestock producers) randomly selected in the Yendi Municipality of the Northern Region. The dependent variable is income and is measured as a continuous variable using total annual household income (in Ghana cedis) obtained from farming (livestock and crop production) and non-farm activities (salaries, remittances, gift, windfall gain and pension).

The independent variables included socio- 
demographic characteristics (age, gender, educational level and household size) and other household income determinants (farm size, tropical livestock unit, access to credit, distance to market and dependency ratio) of the selected smallholder livestock producers. Past studies (Kafle, 2014; Adam and Ohene-Yankyera, 2014; Assa, 2012; Inoni, 2010; Akter, 2011; Ntanyoma, 2010; Naminse, 2010; Yusuf et al., 2008; Alam, 1997) have also used similar dataset.

The independent variable of interest is smallholder livestock production proxied by tropical livestock unit (TLU). The TLU is used to aggregate different species and classes of livestock. It is measured by flock size where one TLU is commonly one live animal with 250 kilogram of weight (see Jahnke et al., 1988). Past studies including Kafle (2014), Inoni (2010) and Ntanyoma (2010) found that TLU has positive influence on household income. In this paper TLU is expected to be positively associated with household income. In the Yendi Municipality farmers practice mixed farming (rearing animals and cultivating crops), hence farm size is another variable of interest included in the dataset. It is measured by the total size of land (in acres) cultivated in a production year. Larger farm sizes are expected to impact positively on household income. However, the limitation with this variable is that the quality of the soil has not been considered, therefore the results should be interpreted with caution. Talukder (2014) and Nzabakenga et al. (2013) did also control for farm size in their studies in Bangladesh and Burundi respectively.

In Northern Ghana peasant farmers depend mainly on family members or dependants (wives, children and other relations living in the house or who depend on household head) for labour in the farm or animal rearing. The relationship between household size and household income is expected to vary. Where dependants take active part in productive activities such as animal rearing and/or farm work then the relationship will be positive. Other studies includ- ing Talukder (2014), Nzabakenga et al. (2013), Inoni (2010), Akter (2011), Ntanyoma (2010) and Naminse (2010) also included household size in their study. Gender is a binary dummy variable which took the value 1 if household head is male and 0 if female. Empirical study suggests that being male or female is likely to impact on household income differently (Anang et al., 2015). Being male is expected to have positive influence on household income compared to females. Previous studies (Kafle, 2014; Inoni, 2010; Ntanyoma, 2010) also included gender in their studies.

With regard to age and educational attainment of household heads, older household heads may have relatively better access to productive resources compared to younger household heads. Resource constraints among younger household heads may affect their output level negatively hence smaller income. However, younger household heads are more able to adopt new technologies quickly relative to the older counterparts. Thus, the relationship between age and household income is expected to be varied. The education variable is measured by number of years a household head has spent in school. The human capital theory has indicated that education, training and experience make a person more productive (Becker, 1964). Education enables individuals to take good and informed decision and make wise choices. It is expected that education will have positive influence on household income. Kafle (2014), Inoni (2010) and Ntanyoma (2010) also controlled for the education variable in their studies.

Other variables we included are distance to market, dependency ratio and access to formal credit. For smallholder farmers, having access to markets as well as proximity (how far farms are from the market center) help to reduce transportation cost. On the other hand dependency ratio measures the number of inactive population (members less than 18 years and above 60 years) in the family. But, it should be noted that in Africa sometimes children as young as 8 or 9 years are used as farm workers. 


\section{Baidoo et al.}

For the present paper, distance to market and dependency ratio variables are expected to have negative relationship with income.

Like all business persons, farmers use credit facilities to expand farm size, pay for land preparation, purchase farm inputs or increase their flock size. Household heads with adequate credit can undertake more than one productive venture which may also increase household income. Therefore, access to credit is likely to increase agricultural output, income and food security (Diagne et al., 2000). In this paper, access to formal credit is measured as a dummy variable and took the value 1 if household head has access to formal credit and 0 if not. We expect access to formal credit to correlate positively with household income.

\section{Model specification}

Past studies have employed several estimation techniques including pooled poisson (Kafle, 2014), ordinary least square (Talukder, 2014; Nzabakenga et al., 2013; Inoni, 2010), endogenous switching (Assa, 2012), multinomial logit (Akter, 2011), propensity score matching (Ntanyoma, 2010) and logistic regression (Yusuf et al., 2008) to study household income issues. For this present paper the dependent variable (annual household income from farming and non-farming activities) is a continuous variable and the whole dataset lend itself to ordinary least square estimation technique. Consequently, we specified the estimation technique as:

$H i n c_{t}-\alpha+\phi T L U_{t}+\gamma x_{t}+s_{t}$

where $H i n c_{i}$ is household income, $T L U_{i}$ is tropical livestock unit (proxy for smallholder livestock production for a particular household), $\chi_{i}$ is a vector of controlled variables consisting of socio-demographic and economic characteristics of smallholder livestock households and other household income determinants. These controlled variables comprise gender $(G E N)$, age $(A G E)$, educational attainment of household head $(E D U C)$, farm size $(F S)$, household size $(H H S)$, distance to market $(D M K T)$, dependency ratio $(D R)$ and access to formal credit $(A F C)$. The coefficients $\phi$ and $\gamma$ provide an estimate of the marginal impact of smallholder livestock production and the other controlled variables on household income respectively. $\varepsilon_{i}$ is an independently and identically distributed error term.

Equation 1 is transformed into natural logarithm as:

$\operatorname{lnHinc}_{i}=a+\varnothing \operatorname{lnTLU_{i}}+\gamma_{1} \ln F S_{i}+\gamma_{2} \ln H H S_{i}+$

$\gamma_{3} G E N_{i}+\gamma_{4} \ln A G E_{i}+\gamma_{5} \ln E D U C_{i}+\gamma_{6} \ln D M K T_{i}$

$+\gamma_{7} \ln D R_{i}+\gamma_{8} A F C_{i}+\varepsilon_{i} \ldots \ldots \ldots \ldots \ldots$

Natural $\log$ is a convenient and robust way of describing relations between two variables. Small changes in the natural log of a variable are directly interpretable as percentage changes. However, the variables gender and access to formal credit were not transformed due to their categorical nature.

\section{RESULTS AND DISCUSSION}

This section presents the descriptive statistics and estimates of the OLS regression used for analysis.

\section{Descriptive statistics}

The descriptive statistics of household heads' characteristics and other determinants of household income are presented in Table 1.

The result indicates that male heads form $94.7 \%$ and this appears to be consistent with the Ghana Statistical Service report in 2014 that there are $84.5 \%$ male household heads as against $15.5 \%$ female heads in the Yendi area (Ghana Statistical Service 2014b). Table 1 reveals that household heads who have primary education or no education at all (0 to 6 years in school) constitute $74.7 \%$ of the respondents whilst those with Junior High School or Middle School Leaving Certificate ( 7 to 9 years in school) represents $23.7 \%$. Only $1.7 \%$ of respondents have Senior High School or GCE Ordinary Level qualification (10 to 12 years in school). As regards marital status, the study 
Smallholder livestock production ... 14

Table 1: Descriptive statistics

\begin{tabular}{|c|c|c|c|c|c|}
\hline Variable & Frequency & Percentage & Min. value & Max. Value & Mean \\
\hline Male & 284 & 94.7 & & & \\
\hline Female & 16 & 5.3 & & & \\
\hline Single & 3 & 1 & & & \\
\hline Married & 279 & 93 & & & \\
\hline Divorced & 4 & 1.3 & & & \\
\hline Widowed & 6 & 2 & & & \\
\hline Separated & 8 & 2.7 & & & \\
\hline $0-6$ years in school & 224 & 74.7 & & & \\
\hline $7-9$ years in school & 71 & 23.7 & & & \\
\hline $10-12$ years in school & 5 & 1.7 & & & \\
\hline Access to credit & 25 & 8.3 & & & \\
\hline No access to credit & 275 & 91.7 & & & \\
\hline Tropical Livestock Unit (kg) & - & - & 1.40 & 24.40 & 4.1580 \\
\hline Farm Size (acre) & - & - & 2.00 & 15.00 & 6.0267 \\
\hline Household Size & - & - & 3.00 & 25.00 & 9.0000 \\
\hline Dependency Ratio & - & - & 0.50 & 3.00 & 1.2997 \\
\hline Distance to Market (km) & - & - & 1.00 & 28.00 & 11.4333 \\
\hline Age of household head & - & - & 28.00 & 71.00 & 47.6400 \\
\hline
\end{tabular}

Source: Authors' computation using field survey data, 2016

found that roughly $93 \%$ were married and only $1 \%$ were single. The economic reasoning in the Ghanaian rural context is that marriage could increase the family size and hence more farm labour.

The mean tropical livestock unit is $4.16 \mathrm{~kg}$ indicating that flock size in aggregation of each household head is $4.16 \mathrm{~kg}$. This suggests that the respondents are actually engaged in smallholder livestock production. On farm size the mean land holding of 6.0267 acres is a little smaller than 6.69 acres reported by Adams and Ohene-Yankyera (2014). Chamberlin (2007) also reported 9.88 acres as the mean for all the three regions in the North (Upper East, Upper West and Northern regions).

The result further shows that the mean household size is 9. This figure is higher than both the reported national average of 4.5 and the Northern Regional average of 7.8 but similar to the Yendi Municipality average of 9.3 reported by Ghana Statistical Service (2014b).

The mean age of respondents was 47.64 years, which is similar to the 47.29 years reported by Adams and Ohene-Yankyera (2014) for Northern Ghana. The minimum and the maximum ages of respondents are 28 years and 71 years respectively. The mean age of approximately 48 years indicates that economically active people are needed to undertake the laborious activities involved in crop-livestock production.

\section{Analysis of results}

To examine the effect of smallholder livestock production on household income, we estimated equation (2) and the results are presented in Table 2.

As expected, the coefficient of the tropical livestock unit (lnTLU) is 0.2727 , it is positive and statistically significant at the $1 \%$ level. This 
Table 2: Estimated OLS regression results

\begin{tabular}{lccc}
\hline Variable & Coefficient & $\begin{array}{c}\text { Robust } \\
\text { Standard Error }\end{array}$ & $\begin{array}{c}\text { Variance Inflation } \\
\text { Factor }\end{array}$ \\
\hline Constant & $8.0050^{* * *}$ & 0.5184 & 1.46 \\
LnTLU & $0.2727^{* * *}$ & 0.0339 & 1.52 \\
LnFS & $0.3894^{* * *}$ & 0.0614 & 1.67 \\
LnHHS & $0.1136^{*}$ & 0.0674 & 1.19 \\
GEN & 0.0376 & 0.0715 & 1.57 \\
LnAGE & -0.1402 & 0.1439 & 1.11 \\
LnEDUC & 0.0875 & 0.0531 & 1.15 \\
LnDMKT & $-0.0733^{* * *}$ & 0.0181 & 1.20 \\
LnDR & $-0.0825^{*}$ & 0.0436 & 1.04 \\
AFC & 0.0083 & 0.0600 & \\
Number of observation $=300$ & \multicolumn{2}{c}{$\mathrm{F}(9,290)$} \\
R-squared & $=.5208$ & $\mathrm{P}$-value (overall) $=0.00001$ & \\
\hline
\end{tabular}

Note: $* * *$ and $*$ denote $1 \%$ and $10 \%$ significance level

suggests that the size of a household livestock has a significant positive influence on household income. A unit increase in tropical livestock unit increases household income by 0.2727 . By implication, increase in livestock production enables farm households to produce and sell more animals as well as animal-source products hence increase in income, ceteris paribus. Our result is consistent with the findings by Kafle (2014) and Ntanyoma (2010).

Regarding farm size (lnFS) and household size (lnHHS), the coefficients show that the two variables have positive and statistically significant association with household income. The coefficients of 0.3894 and 0.1136 indicate that a unit increase in farm size and household size increase household income by 0.3894 and 0.1136 respectively and are significant at $1 \%$ and $10 \%$ respectively. Increase in farm size is likely to increase output of farmers and hence their income. Also, increase in the household size means that there will be more labour to work on farms or rear animals and this is likely to increase household production as well as income. Another reason may be that rural farming activities require more labour inputs to undertake the various farm activities. Therefore households with large members are more likely to cultivate large farm size which could result in more output and more income. The positive relationship between farm size, household size and household income is consistent with the findings by Talukder (2014) and Nzabakenga et al. (2013).

With regard to distance to market (lnDMKT) and dependency ratio (lnDR) the results indicate that they are negatively correlated with household income at $1 \%$ and $10 \%$ significance levels respectively. The coefficient for distance to market center and dependency ratio are 0.0733 and -0.0825 suggesting that a unit increase (decrease) in distance to market center and dependency ratio reduce (increase) household income by 0.0733 and 0.0825 respectively. This further suggests that longer distance to market centers from where production takes place and higher dependency ratio reduce household income ceteris paribus. Longer distance to market centers increases transportation cost which might be a disincentive for household to take their farm produce or domestic animals to market. This will have 
Smallholder livestock production... 16

negative effects on their incomes.

The estimated coefficients from the results show that gender (GEN), age (lnAGE), education (lnEDUC) and access to formal credit (AFC) variables do not have any statistically significant effect on household income. The gender variable has a positive sign but insignificant whilst the age variable has negative sign and statistically insignificant. The education variable is insignificant and could be due to the fact that roughly $93 \%$ of the respondents have very little or no education at all.

The value of the F-statistic (30.62) and the corresponding $\mathrm{p}$-value of 0.00001 obtained from the estimated regression result (See Table 2) indicate that the overall model is statistically significant at $1 \%$ significance level. Diagnostic tests regarding heteroscedasticity, normality and multicollinearity were conducted and the results are presented in Table 3.

Heteroscedasticity and normality tests presented in Table 3 indicate no support for normality problem in this paper. However, there was evidence of heteroscedasticity and hence robust standard errors were estimated for the variables to address this issue. We also tested for multicollinearity among the independent variables using Variance Inflation Factor (VIF) but find no support for it. Multicollinearity is said to exist and is a problem when VIF is greater than 10 (Greene, 2003). The values of the VIF estimated for each variable (see Table
2) is less than 5 which is less than the rule of thumb value of 10.00 .

\section{CONCLUSION AND RECOMMENDA- TIONS}

The main goal of this paper was to examine the effect of smallholder livestock production on household income in the Yendi Municipality of Northern Ghana. Questionnaire were administered to 300 smallholder livestock producers and ordinary least square regression (OLS) was applied to the dataset. Our descriptive statistics revealed interesting findings. First, $98.4 \%$ of smallholder livestock producers have attained low level of education (Junior High School certificate).

The OLS regression results revealed that smallholder livestock production has positive and statistically significant effect on household income. The results show other important findings. For example household income is positively associated with farm size and household size. This paper has also shown that distance to market center and dependency ratio have negative relationship with household income. However, this paper did not find significant relationship between gender, age, education and access to formal credit and household income.

This paper has important policy implications for Ghana. First, smallholder livestock production has positive effect on household income and thus has the potential of alleviating poverty among poor rural people in Ghana.

Table 3: Diagnostic test

\begin{tabular}{lc}
\hline \multicolumn{1}{c}{ Test } & Statistics \\
\hline Heteroscedasticity & $89.05(0.0011)$ \\
Normality: & $6.52(0.6870)$ \\
Skewness & $0.44(0.5078)$ \\
Kurtosis & No multicollinearity \\
Multicollinearity &
\end{tabular}

Note: In parentheses are the probability values. 


\section{Baidoo et al.}

Therefore, policies to promote smallholder livestock production like livestock subsidy programmes should be designed and implemented taking into account its sustainability. Also access to market in terms of distance should be an area of concern for policy makers in order to serve as a motivating factor for people to engage in livestock production. Finally, policies that will help farmers to cultivate larger acres of land such as good and flexible land tenure arrangements are recommended to enable farmers to cultivate larger farm sizes in order to get more output. This is likely to increase household incomes and thus reduce poverty in northern Ghana.

The paper has made significant contribution to factors that influence household income in Northern Ghana. However the results should be interpreted with caution for policy purposes since it covered just one out of the three regions in Northern Ghana. It is recommended that future research should concentrate in the Upper East and Upper West regions so that the results could be compared.

\section{REFERENCES}

Aber, J. L., Bennett, N. G., Conley, D. C. and $\mathrm{Li}$, J. (1997). The effects of poverty on child health and development. Annual Review of Public Health, 18(1): 463-483.

Adams, F. and Ohene-Yankyera, K. (2014). Socio-economic characteristics of subsistent small ruminant farmers in three regions of northern Ghana. Asian Journal of Applied Science and Engineering, 3(3): 351-364.

Akter, S. (2011). Livestock based livelihoods and pathways out of poverty: the case of smallholder farmers in Bangladesh. In 85th Annual conference of Agricultural Economics Society. Warwick University.

Alam, J. (1997). Impact of smallholder livestock development project in some selected areas of rural Bangladesh. Livestock Research for Rural Development, 9(3): 1-14.
Anang, B. T., Sipiläinen, T., Bäckman, S. and Kola, J. (2015). Factors influencing smallholder farmers' access to agricultural microcredit in Northern Ghana. African Journal of Agricultural Research, 10(24): 2460-2469.

Asafu-Adjei, K. and Dantankwa, A. (2001). Policies for improving the competitiveness of smallholder livestock producers in Ghana. challenges and opportunities. In Proceedings of a workshop policies for improving the competitiveness of smallholder livestock producers in the central corridor of West Africa. Implications for trade and regional integration. Abidjan, Cote d'ivore. International Livestock Research Institute, $18^{\text {th }}$ September, 2001.

Assa, M. (2012). Poultry production and rural poverty among small-scale farmers in Mzimba District of Malawi.179

Becker, G. S. (1964). Human Capital: A Theoretical and Empirical Analysis. New York: Columbia University Press for the National Bureau of Economic Analysis.

Brooks-Gunn, J. and Duncan, G. J. (1997). The effects of poverty on children. The future of children, 55-71.

Chamberlin, J. (2007). Defining Smallholder Agriculture in Ghana: Who Are Smallholders, What Do They Do and How Are They Linked with Markets? GSSP Background Paper 6. International Food and Policy Research Institute, Washington, DC.

Chen, S. and Ravallion, M. (2008). The developing world is poorer than we thought, but no less successful in the fight against poverty, World Bank Policy Research Working Paper no 4703

Diagne, A., Zeller, M. and Sharma, M. (2000). Empirical measurements of households' access to credit and credit constraints in developing countries: Methodological is- 
Smallholder livestock production... 18

sues and evidence. International Food Policy Research Institute. Washington, DC.

Eamon, M. K. (2001). The effects of poverty on children's socioemotional development: An ecological systems analysis. Social Work, 46 (3): 256-266.

Food and Agriculture Organization (2012). Faostat. Disponível em:< http://faostat. fao. org>. Acesso em, 14. Accessed, $15^{\text {th }}$ August, 2016.

Ghana Statistical Service. (2014c). Ghana Living Standard Survey (GLSS Round 6): Poverty Profile in Ghana (2005-2013). GSS, Accra, Ghana.

Ghana Statistical Service, (2014a). Ghana Living Standards Survey Round 6 (GLSS6): Poverty Profile in Ghana. GSS, Accra, Ghana.

Ghana Statistical Service (2014b). 2010 Population and Housing Census: District Analytical Report -Yendi Municipality. GSS, Accra, Ghana.

Greene, W. H. (2003). Econometrics Analysis. Fifth Edition, Prentice Hall, Upper Saddle River, New Jessey.

Guo, G. and Harris, K. M. (2000). The mechanisms mediating the effects of poverty on children's intellectual development. Demography, 37(4): 431-447.

Hoynes, H. (2012). Poverty: Facts, Causes and Consequences. Joe Tiao Lecture, Kansas State University, University of California, Davis.

Inoni, O. E. (2010). Effects of Small-holder Livestock Production in Reducing Rural Poverty in the Central Agricultural Zone of Delta State, Nigeria. Libyan Agriculture Research Center Journal International, 1(3):171-176.
Jahnke, H. E., Tacher, G., Kiel, P. and Rojat, D. (1988). Livestock production in tropical Africa, with special reference to the tsetseaffected zone. Livestock production in tsetseaffected areas of Africa, 3-21.

Kafle, K. R. (2014). Is There More than Milk? The Impact of Heifer International's Livestock Donation Program on Rural Livelihoods: Preliminary Findings from a Field Experiment in Zambia. In 2014 Annual Meeting, July 27-29, 2014, Minneapolis, Minnesota (No. 170629). Agricultural and Applied Economics Association.

Klebanov, P. K., Brooks-Gunn, J. and Duncan, G. J. (1994). Does neighborhood and family poverty affect mothers' parenting, mental health, and social support?. Journal of Marriage and the Family, 441-455.

MOFA/DFID (2002). The Role of Livestock in Rural Livelihoods in Ghana: Final Report; presented to Ministry of Food and Agriculture (MOFA) and Department for International Development (DFID), Accra.

Naminse, E. Y. (2010). The Impact of Ruminant Production on Household Income and Food Security in Ghana. Symposium Paper, University for Development Studies Faculty of Agriculture Department of Agribusiness Management and Finance. $19^{\text {th }}-20^{\text {th }}$ June, 2010, Boston, USA.

Ntanyoma, R. D. (2010). The effect of livestock production on poor and smallholder farmers' income in Rwanda: Case of 'One Cow One Family Program', ISS, The Hague.

Nzabakenga, A., Feng, L. X. and Yaqin, H. (2013). Agricultural Income Determinants among Smallholder Farmers: Case of Northern Part of Burundi. Asian Journal of Agriculture and Rural Development, 3(11): 780.

Talukder, D. (2014). Assessing Determinants of Income of Rural Households in Bangladesh: 


\section{Baidoo et al.}

A Regression Analysis. Journal of Applied Economics and Business Research, 4(2): 80106.

Udo, H. M. J., Aklilu, H. A., Phong, L. T., Bosma, R. H., Budisatria, I. G. S., Patil, B. R., Samdup, T. and Bebe, B. O. (2011). Impact of intensification of different types of livestock production in smallholder croplivestock systems. Livestock Science, 139: 22 -29 .

World Bank (2007). Global Economic Prospects (2007). World Bank, Washington, DC

Yoshikawa, H., Aber, J. L. and Beardslee, W. R. (2012). The effects of poverty on the mental, emotional, and behavioral health of children and youth: implications for prevention.
American Psychologist, 67(4): 272.

Yusif, H. (2015). Does high school elective mathematics have any effect on performance in University economics in Ghana?. Journal of Science and Technology (Ghana), 35(3): 98-105.

Yusif, H. M. and Ali, B. (2013). Academic performance of less endowed high school students in the Kwame Nkrumah University of Science and Technology. Journal of Science and Technology (Ghana), 33(2): 104117.

Yusuf, S. A., Adesanoye, A. O. and Awotide, D. O. (2008). Assessment of poverty among urban farmers in Ibadan Metropolis, Nigeria. Journal of Human Ecology, 24(3): 201-207. 